\title{
Erratum to: Increased risk of serious infections in women with osteopenia or osteoporosis treated with denosumab
}

\author{
K. A. Toulis • A. D. Anastasilakis
}

Published online: 5 February 2010

(C) International Osteoporosis Foundation and National Osteoporosis Foundation 2010

\section{Erratum to: Osteoporos Int}

DOI 10.1007/s00198-009-1145-1

Owing to an error in typesetting, the third sentence of this letter contained a false CI value. The correct version of the sentence is:

Updating this meta-analysis [2] with the latest data from the FREEDOM trial [1], the risk of serious infections remained significantly higher for the denosumab group [Mantel-Haenszel risk ratio $(\mathrm{M}-\mathrm{H} \mathrm{RR})=1.26$, confidence interval $(\mathrm{CI})=1.01-1.57 ; p=0.04, \mathrm{I}^{2}=22.8 \%$, Fig. 1].

The online version of the original article can be found at http://dx.doi. org/10.1007/s00198-009-1145-1.

K. A. Toulis $(\bowtie)$

Division of Endocrinology and Metabolism, Medical School,

Aristotle University of Thessaloniki,

Antheon 2, Agios Pavlos,

Thessaloniki 55438, Greece

e-mail: toulis@endo.gr

\author{
A. D. Anastasilakis \\ Division of Endocrinology \& Metabolism, \\ 424 General Military Hospital, \\ Thessaloniki, Greece \\ e-mail: anastath@endo.gr
}

